\title{
FUTURE GENERATION MILITARY AVIONICS FIBER OPTICS PHOTONICS PACKAGING CHALLENGES
}

\author{
Mark W. Beranek, Naval Air Systems Command, Patuxent River, Maryland
}

\begin{abstract}
The military/aerospace platform operational environment challenges the creativity of fiber optic module packaging engineers as they endeavor to develop and mature new active and passive singlemode fiber optic and photonic components for next generation avionics networking applications. Low sales and manufacturing volumes inherent to avionics combined with lack of standard interface specifications for current and next generation fiber optic local area network architectures and subsystems makes it difficult for avionics suppliers to justify upfront research and development (R\&D) investment in advanced fiber optics and photonics packaging technology.

Collaboration between commercial industry photonic component and advanced packaging R\&D and military/aerospace photonic component and advanced packaging $R \& D$ has proven to be a successful formula for mitigating technical and business risk on military/aerospace programs, and gives best value components for military avionics applications. As the avionics industry migrates from multimode fiber optic point-to-point link based systems to fully-interconnected single-mode wavelength division multiplexed-based local area network (WDM LAN) architectures, it naturally follows that similar collaborations will be needed to realize the technical and business success of the avionics WDM LAN.

Currently, the SAE Avionics Systems Division (SAE WDM LAN), the IEEE Avionics Fiber Optics and Photonics Conference (AVFOP), and the ARINC Fiber Optics Subcommittee are endeavoring to coordinate avionics WDM LAN standardization efforts internationally via formal committee meetings and conference events.
\end{abstract}

U.S. Government work not protected by U.S. Copyright.

\section{First Generation Legacy Avionics Packaging Lesson's Learned}

During the first generation legacy avionics packaging era (1987 to 1997), MIL-STD-883 Test Methods and Procedures for Microelectronics and MIL-STD-38534 General Specification for Hybrid Microcircuits provided significant guidance to engineers interested in packaging fiber optic transmitters, receivers and transceivers for military/aerospace avionics applications. A 1990 paper from AT\&T Bell Laboratories presented some of the first packaging results for a militarized megabit/second LED transmitter [1]. The Bell Labs paper described a thin, hermetically sealed package form-factor built for military avionics applications invoking the Standard Electronic Module (SEM-E) line replaceable module (LRM) standard.

A 1990 paper from Boeing presented early results packaging a multi-channel InGaAs photodetector array for parallel-bus optical interconnects [2].

A 1991 paper from Boeing presented some of the first packaging results for a militarized gigabit/second laser diode transmitter [3]. This paper described the pros and cons of utilizing thermoelectric coolers (TECs) inside laser transmitter packages, where the primary con being the inability to attain a low package height requirement of 0.12 inches due to the height of the TEC. A $0.98 \mu \mathrm{m} \mathrm{InGaAs/GaAs} \mathrm{strained} \mathrm{layer}$ quantum well laser diode operating at $125^{\circ} \mathrm{C}$ was also described whereby operation up to $200^{\circ} \mathrm{C}$ was demonstrated. Using a high temperature laser diode in conjunction with a rear-facet monitor photodetector and a bias-current compensation circuit obviated the need for a TEC in the laser transmitter package [4].

1991 to 1993 publications from Harris Corporation outlined the state-of-the-art in military avionics fiber optic transmitter and receiver packaging for the fiber-optic High Speed Data Bus (HSDB) [5 - 7]. The military SEM-E LRM form 
factor steered the development of the fiber optic HSDB and Fiber Optic Transmitter and Receiver (FOTR) packaging for the Air Force F-22 Raptor tactical fighter jet platform. A compact detachable fiber optic connector designed to be compatible with an active alignment fiber optic stub-based packaging scheme was developed for attaching a removable fiber optic pigtail to the transmitter and receiver optical interfaces. A physical contact (PC) type fiber optic interface based on ceramic ferrules and a ferrule alignment sleeve enabled connector mating and de-mating [8].

In parallel with the early military aircraft packaging technology initiatives described above, engineers were engaged in the development of fiber optic module packaging technology for space platforms (such as the International Space Station and various satellites) and the Boeing 777 commercial air transport jet [ $9-11]$.

All of the above described packaging developments were aimed at multimode fiber optic links (either LED or laser diode sources). During this same era however, a single-mode fiber pigtailed transmitter and receiver module technology based on an unisolated and uncooled InGaAs/AlGaAs Fabry-Perot laser diode and rear-illuminated InGaAs/InP Schottky photodiode was developed by SDL for space photonics applications [12-13].

The ARPA Optoelectronic Technology Consortium (OETC) program demonstrated a 32element vertical cavity surface emitting laser (VCSEL) parallel array transmitter and receiver packaging technology operating at $500 \mathrm{Mb} / \mathrm{s}$ per channel [14]. Soon thereafter, under the ARPAsponsored Avionics Optoelectronic Module Technology program, Boeing initiated a collaborative study with Honeywell to understand the reliability and performance limits of uncooled VCSEL devices for potential use in multimode fiber-based avionics applications [15].

Back in 1997, the primary issue limiting widespread fiber optics and photonics technology insertion on aerospace platforms was affordability (owing to low volume use and little packaging standardization/commonality across the various avionics applications) [16].

\section{Second Generation Legacy Avionics Packaging Lesson's Learned}

During the second generation legacy era (1998 to 2007), significant effort went in to tackling the packaging and manufacturing affordability issue identified in 1997. A number of follow-on programs ensued including the DARPA Optical Micro-Networks (OMNET) program.

Some of this work was reported by Air Force Research Lab and Boeing at the 18th DASC [17]. Boeing publications described transmitter and receiver optical subassembly passive alignment packaging techniques based on wide operating temperature range surface emitting LEDs, VCSELs, PIN photodiodes, multimode optical fiber, silicon optical bench technology, precision ceramic optoelectronic device submount molding technology, and a detachable package connector [18].

The NIST Advanced Technology Programsponsored and National Center for Manufacturing Sciences-led Precision Optoelectronics Assembly Consortium (comprising participation by industrial robot manufacturer Adept Technology along with Boeing, SDL, New Jersey Institute of Technology and commercial-sector technology providers Corning, Lucent Technologies, Motorola and New Focus) endeavored to combine aerospace packaging technology requirements and expertise with commercial fiber optic module packaging and manufacturing automation best practices [19]. On another program supported by DARPA, McDonnell Douglas (now Boeing) developed a micro-electromechanical system (MEMS) based in-package fiber optic aligner device which, in theory, obviated the need for external fiber optic module optical subassembly manufacturing hardware, process and infrastructure development [20]. The NIST and DARPA programs were deemed technically successfully, but did not directly result in any significant cost reductions for avionics.

In parallel with government-sponsored programs, industry also began looking at ways to utilize even lower cost commercial packaging technology to overcome the affordability challenges inherent in high performance avionics-grade fiber optic transmitter and receiver modules. At Boeing, a new avionics transmitter and receiver packaging 
concept based on chip-on-board (COB) technology resulted in a lower-cost design [21]. The chip-onboard package utilized large format multi-chip module laminate (MCM-L) substrates and glob top encapsulation of the integrated circuits. The LED and PIN photodetector devices were hermetically sealed in $\mathrm{TO}$-can $\mathrm{ST}^{\mathrm{TM}}$ fiber optic connector receptacles.

Teledyne Electronic Technologies reported on a similar approach whereby the hermetic FOTR transmitter package developed by Harris Corporation for the F-22 Raptor was re-packaged using a MCM-L substrate and encapsulation [22].

A few years later Boeing reported on the application of COTS optoelectronics and MCM-L and COB packaging technology in a prototype 12channel $1.0625 \mathrm{~Gb} / \mathrm{s}$ Fibre Channel receiver module based on ball-grid array module-to-board interconnect [23].

Unisys (now Lockheed Martin) under the Optical Backplane Interconnect System (OBIS) project awarded by the U.S. Navy under NAVAIR's Advanced Avionics Systems and Technology program proposed a fiber optic module package with a detachable connector similar to that used in the FOTR and HSDB modules developed by Harris Corporation for the F-22 Raptor and by Boeing under the ARPA Avionics Optoelectronic Module Technology program [24-25]. The detachable fiber optic connector continues to be viewed as a key enabling package sub-component to attain lower-cost deployment of avionics fiber optics and photonics technology. A universal detachable fiber optic module connector pigtail of varying lengths (for both hermetically-sealed and non-hermetically sealed modules) can be applied across a broad range of weapons replaceable assembly (WRA) and line replaceable unit/module (LRU/LRM) avionics applications.

\section{Modern COTS Gigabit-Era VCSEL Transceiver Packaging}

As the operating temperature range of VCSELbased small form factor (SFF) gigabit fiber optic transceiver packages evolved from their original 0 to $+70{ }^{\circ} \mathrm{C}$ range to wider ranges, the avionics industry began to take notice.
Work performed at Harris Corporation showed that COTS transceivers packaged to commercial standards could be post-production modified to meet selected avionics applications. Careful transceiver screening and qualification regimen enabled the transition of the SFF gigabit fiber optic transceiver to the avionics sector [26]. As was envisioned in the early-1990s, the aerospace industry was now able to (relatively cost effectively) leverage the commercial fiber optics /optoelectronics sector to insert high-speed gigabit per second digital fiber optic links onboard aircraft.

The detachable connector SFF transceiver package interface shown on the left of Figure 1 is based on an adaptation of the unibody plastic injection molded optical subassembly developed by IBM for commercial-sector local area and storage area networks [27]. This interface was specifically developed to avoid the packaging and manufacturing costs associated with conventional fiber optic transmitter / receiver optical subassembly pigtailing manufacturing based on active alignment and hermetic sealing.

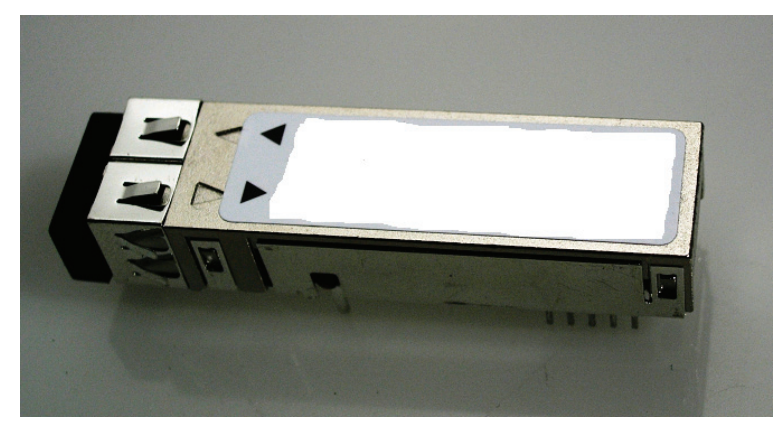

Figure 1. COTS Gigabit Transceiver (Detachable Connector Interface on Left)

Although technically successful, the original cost reduction argument for the COTS transceiver itself (including the detachable connector interface) has been left somewhat tainted by the obsolescence factor inherent in the commercial optoelectronics sector business space.

\section{Gigabit-Era VCSEL Transceiver Packaging Challenges Ahead}

Moving ahead to 2008 and beyond, the fiber optic module packaging challenges for next generation gigabit transceiver components are no 
different today than they were a decade ago when development of LED-based megabit transmitter/ receiver/transceiver packaging technology was the challenge. The paper "Challenges for developing low-cost avionics/aerospace-grade optoelectronic modules" presented by Boeing in 1996 gives significant technical insight into the problem that industry faces today [28].

The primary issues limiting widespread BITcapable VCSEL transceiver gigabit fiber optics and photonics technology insertion are summarized as follows:

- COTS obsolescence / re-qualification costs,

- Cost of COTS screening and ruggedization,

- SFF transceivers not really SFF $(>0.200$ in package height),

- No built-in test (BIT) for cable plant fault isolation,

- Non-use of MSA SFF-8472 diagnostics for fault detection and link health monitoring [29].

Future BIT-capable single wavelength optoelectronic transceiver packages are forecasted to incorporate holistic design concepts whereby BIT circuit integration, optoelectronic packaging integration, high-density detachable connector integration, and optical time domain reflectometry (or optical frequency domain reflectometry or other techniques) are applied [30]. Figure 2 illustrates a potential BIT-capable transceiver package solution under development by Ultra Communications which includes four transmitter and receiver (dualquad) fiber optic channels and features -50 to +100 ${ }^{\circ} \mathrm{C}$ operation.

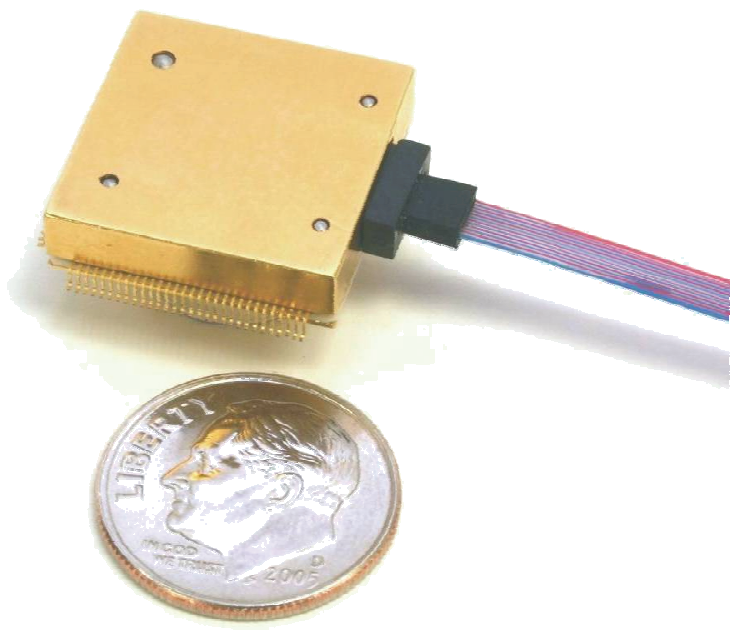

\section{Figure 2. BIT-Capable Dual-Quad Transceiver Package Concept}

To be considered relevant for avionics, the BIT-capable transceiver package is expected to enable the realization of fault detection and fault isolation percentages greater than or equal to $95 \%$ [31]. A significant influx of manufacturing R\&D investment will be required to realize a fully qualified BIT-capable connectorized quad transceiver package solution for avionics/aerospace applications.

\section{Avionics WDM LAN Photonic Component Packages}

Future avionics WDM LAN photonic component packages are forecasted to evolve in generational steps. It is very likely that first generation packages will not have BIT capability owing to the immaturity of BIT-capable WDM LAN system concepts and the SAE WDM LAN standard. To the author's knowledge there are no programs in existence developing BIT-capable WDM LANs, particularly for avionics applications where fault detection and isolation percentage requirements are $95 \%$ or greater.

The current state of WDM photonic integrated circuit technology for implementing potential avionics WDM LAN functions such as tunable wavelength laser data transmission, wavelength filtering, wavelength add/drop, and wavelength conversion requires tight temperature controlling 
circuits to maintain compliance with the ITU grid channel spacing $(0.8 \mathrm{~nm}, 1.6 \mathrm{~nm}, 3.2 \mathrm{~nm}$, etc.).

Figure 3 illustrates a low-profile, wide operating temperature range tunable laser package concept under development at OptoNet. This hermetically sealed package has a much smaller footprint (length, width and height) compared to legacy / first generation wavelength-selected distributed feedback laser and wavelength-tunable laser butterfly packages. Small footprint hermetic packaging similar to the OptoNet package design is expected to be applicable in other temperaturedependent device packaging scenarios including tunable wavelength filters and wavelength converters.

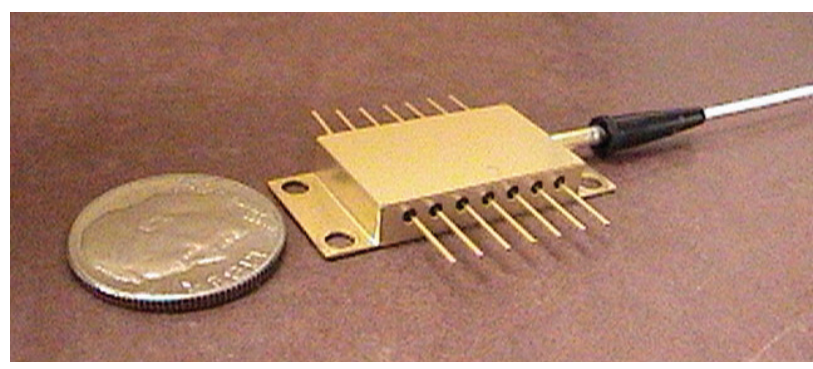

Figure 3. Tunable Laser Package Concept

Second generation avionics WDM LAN packages will likely incorporate detachable single mode connectors. Second or third generation packages should enable the optical BIT function in military avionics systems. Passive add/drop multiplexers and active high-speed optical switches may or may not require TECs and hermeticity. In cases where TECs and hermeticity are not needed it may then be prudent to consider engineering plastics or ceramics as a lower cost packaging materials option in favor of gold plated Kovar, ${ }^{\mathrm{TM}}$ copper-tungsten alloy or other specialty alloys.

\section{Advanced Avionics WDM LAN Photonic Components}

In the foreseeable future, military avionics photonics technology research will address highspeed BIT-capable active and passive WDM LAN component development and packaging. The research will focus on both developmental and life cycle cost factors for digital and RF photonic components. Factors to consider include reliability, durability, installability, interoperability, maintainability, producibility, quality, safety, supportability, testability and cost without sacrificing environmental and optical performance. Advanced packaging development should initially focus on polarization independent versions of the high priority devices listed in Table 1 [32].

Table 1. Avionics WDM LAN Photonic Device Packaging Candidates

\begin{tabular}{|l|l|}
\hline Package/Module Type & Current Priority \\
\hline $\begin{array}{l}\text { Bi-Directional Add-Drop Mux } \\
\text { (BADM) }\end{array}$ & HIGH \\
\hline IPON / LBIC (or derivative) & HIGH \\
\hline Optical Switch & HIGH \\
\hline $\begin{array}{l}\text { Reconfigurable Optical } \\
\text { Add-Drop Mux (ROADM) }\end{array}$ & LOW \\
\hline Tunable Filter & HIGH \\
\hline Tunable Laser Transmitter & HIGH \\
\hline Tunable Receiver & LOW \\
\hline Wavelength Converter & HIGH \\
\hline Wavelength Selective Switch & LOW \\
\hline
\end{tabular}

Priorities listed in Table 1 may change in the future depending on the evolution of the avionics industry's WDM networking technology development roadmap and avionics WDM LAN modeling, simulation, and laboratory test results. External influences on this prioritization could also include the SAE WDM LAN standard, new photonic integrated circuit device developments, and the maturity of the devices indicated by technology (TRL) and manufacturing readiness (MRL).

The candidate tunable filter, tunable laser transmitter, tunable wavelength converter, and bidirectional add/drop multiplexer components listed in Table 1 are described in the following sections.

\section{Tunable Filter}

A generic tunable filter block diagram is shown in Figure 4. Conceptually the filter is a three-terminal active device with one fiber input 
channel and two fiber output channels (the output channels being a passed channel (or express channel) and an output channel). The purpose of the filter is to dynamically route one or more incoming wavelengths from the input channel to a specific output channel [33-34]. Light from the output channel is transmitted down an optical fiber into a digital fiber optic receiver. The remaining unfiltered wavelengths (express channel wavelengths) transparently pass-through / transmitthrough the filter device back to a fiber optic bus or link.

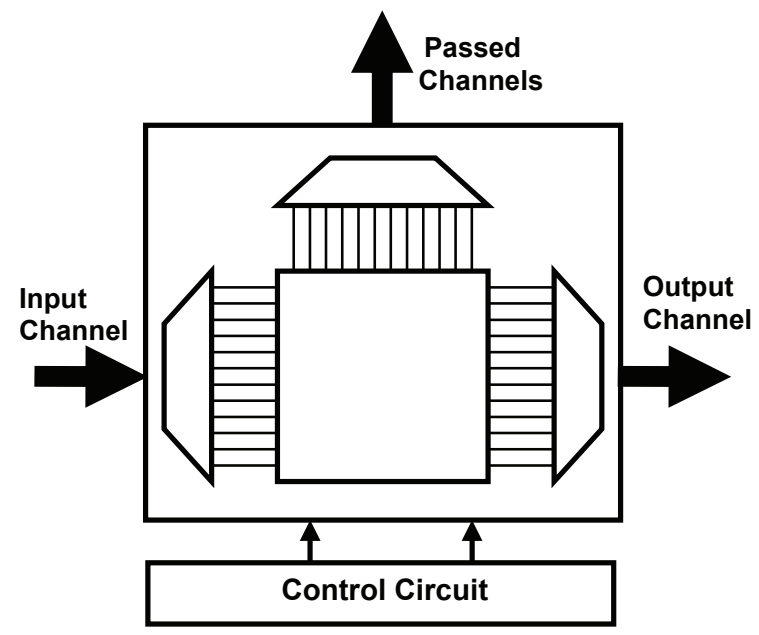

Figure 4. Tunable Filter Block Diagram

\section{Tunable Laser Transmitter}

A generic tunable laser transmitter is shown in

Figure 5. Conceptually the laser transmitter is a one terminal active device with one output channel.

The laser can be tuned to output a specific wavelength depending on commands given to the laser chip from the control circuit [35]. Commercial (non-avionics) operating temperature range devices outputting at least 32 tunable wavelengths at 100 $\mathrm{GHz}$ channel spacing are available in the market.

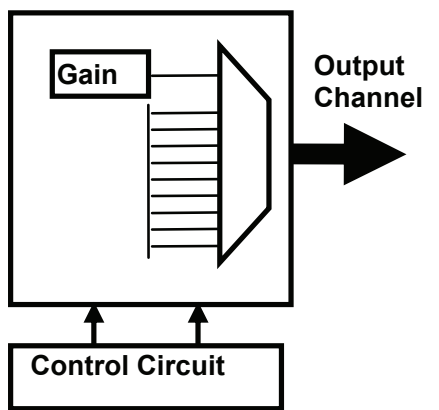

Figure 5. Tunable Laser Transmitter Block Diagram

\section{Tunable Wavelength Converter}

A generic tunable wavelength converter is shown in Figure 6. Conceptually the wavelength converter is a two terminal active device with one input channel and one output channel. The input channel can be broadband light (i.e., emanating from the $1550 \mathrm{~nm} \mathrm{C}$-band). The output channel laser can be tuned to output a specific wavelength depending on commands given to the laser portion of the wavelength converter chip from the control circuit. Fully-packaged tunable wavelength converter devices were used as part of an avionics WDM network in-flight demonstration under the DARPA Chip-Scale WDM program [36].

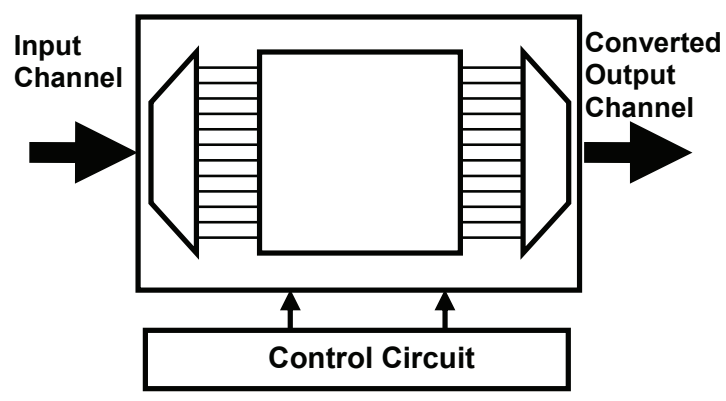

Figure 6. Tunable Wavelength Converter Block Diagram

\section{Bi-Directional Add/Drop Multiplexer}

A generic bi-directional add/drop multiplexer (BADM) is shown in Figure 7. The solid arrowed lines indicate "add" wavelengths whereas the dashed arrow lines indicate "drop" wavelengths. The two two arrowed lines indicate bi-directional transmission of wavelengths through the BADM. 


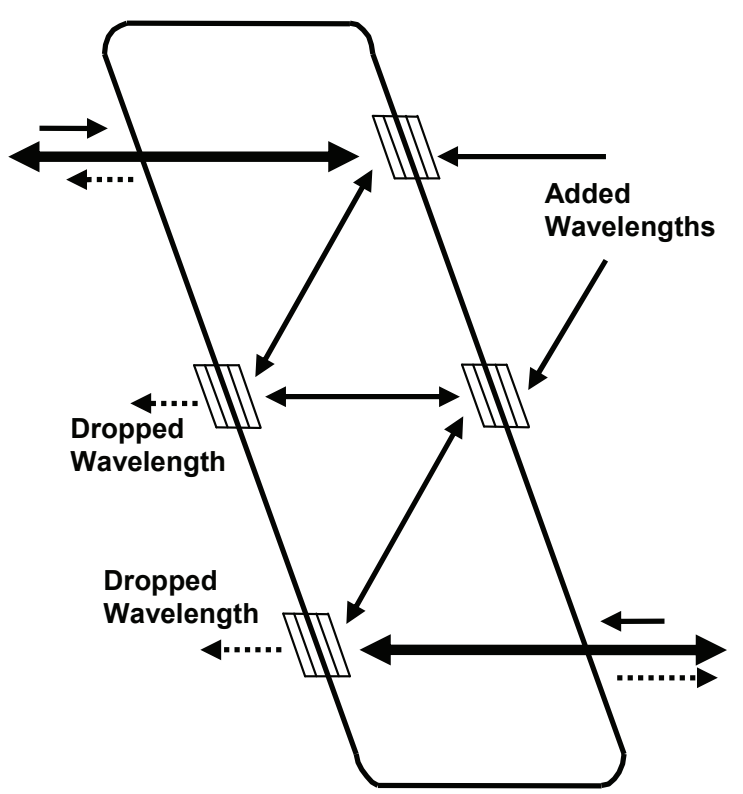

Figure 7. BADM Block Diagram

Conceptually the BADM is a custom fabricated passive device with application specific numbers of fiber optic inputs and outputs. BADMs support the routing of multiple wavelengths in two directions (bi-directionally) on a single fiber optic bus [37-38].

\section{Avionics WDM LAN Photonic Components Packaging Challenges Ahead}

The performance and life cycle cost benefits of WDM LAN technology applied to next generation avionics are well recognized by the aerospace industry [39]. With the demise of MIL standards, and with the current immaturity of the SAE ASD AS5659 WDM LAN standard, we continue to reside are in a network interface standardization/ commonality vacuum. Today this vacuum condition is healthy as it breeds opportunity for significant breakthrough innovation in the avionics fiber optics and photonics component R\&D sector, including WDM component packaging innovation.

A WDM LAN backbone based on BIT-capable tunable filter, tunable laser transmitter, tunable wavelength converter, and bi-directional add/drop multiplexer photonic integrated circuit and hybridization technology can pave the way toward realization of next generation avionics LAN network interface and protocol standards.
Significant technology readiness maturity is needed before the AS5659 standard can be completed and applied on an actual production aerospace platform.

The focus on development of both cooled and uncooled tunable filter, wavelength converter, and laser devices needs to sharpen, as does the packaging of such devices in a size, weight and power form factor suitable for avionics. Packaging development of a connectorized BADM also needs to advance beyond its state of the art in the commercial sector. Manufacturing technology will be needed to move the aforementioned packaging technologies from the laboratory to a cost-effective manufacturing and supply chain infrastructure.

The benefits of the tunable all-optical filter and wavelength converter devices combined with tunable laser transmitter and custom configured BADM devices are based on well-established avionics LAN technology first principles, namely:

- Connectivity

- Latency

- Re-Configurability

- Scalability

- Redundancy

- Reliability

- Maintainability

- Supportability

- Obsolescence Avoidance.

To be practical for avionics, the tunable filter and wavelength converter devices must be capable of processing optical signals without conversion to electronics (avoid optical-to-electrical-to-optical conversion). To be practical for avionics, the tunable filter, wavelength converter, tunable laser, and BADM devices must be packaged to operate over a wide temperature range (i.e., -40 to $100{ }^{\circ} \mathrm{C}$ minimum) and pass stringent temperature cycling, thermal shock, vibration, and humidity cycling qualification. The packages must be connectorized, have a small footprint, consume minimum power (to minimize the needed for external or internal cooling), exhibit low insertion loss and high dynamic range. 
The development and application of integrated WDM optics (or WDM lightguide circuits) technology requiring little or no temperature control is needed to minimize packaging, manufacturing and qualification costs, and reduce the barriers to industry acceptance and transition of WDM technology to future generation avionics systems.

Most of today's WDM components (i.e. tunable laser diodes, distributed feedback laser diodes and wavelength converters) utilize inpackage thermoelectric coolers (TECs) to temperature stabilize the devices for gigabit operation. TECs function as miniature electrically controlled heat pumps. They consist of two ceramic parallel plates (a cold side plate and a hot side plate) separated by semiconductor thermoelements (i.e., bismuth telluride). The thermoelements are connected electrically in series and thermally in parallel. Applying a DC bias to the thermo-elements causes a decrease in cold side temperature and an increase in hot side temperature. Heat is transferred from the hot side plate to the package base or sidewall via conduction.

TEC reliability is proven for avionics. However TEC power consumption is still an open issue that has yet to be resolved by the avionics fiber optic module and WRA, LRU and LRM packaging engineering communities. Avionics packaging engineers need to find new ways to remove or tolerate the heat generated by the TEC's hot side plate inside the package. Onboard liquid and forced air cooling provides a thermal management solution, however not all avionics applications can tolerate the added cost, power and weight penalties associated with external cooling.

\section{Conclusion}

Built-in test capable enabling WDM LAN components continue to be relatively immature with respect to device performance, packaging and manufacturability. A new wave of device and packaging research and development is needed to realize a viable WDM LAN "building block" technology solution for avionics. Specific focus on packaged active tunable filter, wavelength converter, and laser devices, and passive BADM devices, is needed to reach technology readiness level 5 (TRL 5) and TRL 6 in a timeframe consistent with the development and completion of the SAE AS5659 standard.

To reach TRL 5 the components must be integrated so that the technology can be tested in a simulated environment. To reach TRL 6 the components must be well beyond a breadboard / research prototype state, and testable in a high fidelity laboratory environment or simulated operational environment. Significant collaboration between academia, industry and the government continues to be needed to reach TRL 5 for application onboard future generation avionics / aerospace platforms.

\section{References}

[1] M.S. Acarlar, J.K. Plourde, G.J. Steiner and M. Voitek, "Physical design of the ODL ${ }^{\circledR} 250 \mathrm{H}$ militarized surface mount optical data link," Proc. $40^{\text {th }}$ IEEE Electronic Components and Technology Conference, pp. 218-221, 1990.

[2] E.Y. Chan, M. Tanielian, A. Popoff, D. Self, R. $\mathrm{Fu}, \mathrm{A}$. Burnett, and C.S. Hong, "High uniformity, low cost packaging of multi-channel InGaAs photodetector array for parallel-bus optical interconnects," Proc. IEEE LEOS '90 Conference, pp. 335-336, 1990.

[3] D.K. Smith, C.S. Hong and S. Ray, "Multi-Gbps fiber-optic transmitter and receiver for military avionics applications," Proc. of SPIE, vol. 1582, pp. 208-214, 1991.[4] R.J. Fu, C.S. Hong, E.Y. Chan, D.J. Booher and L. Figueroa, "High-temperature operation of a InGaAs strained quantum well lasers," IEEE Photonics Tech. Lett., vol. 3, no. 4, pp. 308-310, April, 1991.

[5] R. Uhlhorn, "Fiber-optic interconnect and component packaging for the next generation of aerospace platforms," Proc. $43^{\text {rd }}$ IEEE Electronic Components and Technology Conference, pp. 974982, 1993.

[6] R. Uhlhorn, "The fiber optic high speed data bus for a new generation of military aircraft," IEEE $L C S$, vol. 2, no. 1, pp. 36-45, 1991.

[7] J.E. Schroeder, N.L. Christian and B. Cotti, "Optical nterconnection and packaging technologies for advanced avionics systems," IEEE Aerospace and Electronic Society Systems (AESS) Magazine, vol. 7, no. 9, pp. 5-9, 1992. 
[8] J. Smous, "Multi-chip module detachable fiber optic," Standard Hardware Acquisition and Reliability Program, Advanced Photonic Technology Workshop, Department of the Navy, 1993.

[9] R.K. Bonebright, J.H. Kim, R. Hughes, J.W. Clement, T.M. Bocek, E.Y. Chan, J. Nitardy and C.S. Hong, "Development of dual-rate MIL-STD 1773A data bus transceiver," Proc. of SPIE, vol. 2811, pp. 142-153, 1996.[10] D.E. Anderson and M.W. Beranek, "777 optical LAN technology review," Proc. $48^{\text {th }}$ IEEE Electronic Components and Technology Conference, pp. 386-390, 1998.

[11] G.L. Abbas, C.S. Hong, R.W. Huggins, G.E. Miller, C.R. Porter, S. Ray, M.C. Reddy, D.K. Smith and L. Figueroa, "Photonics technology for avionics systems," Proc. of SPIE, vol. 2148, pp. 280-291, 1994.

[12] R. Nagarajan, B. Li, W.J. Sha, K. Dzurko and R. Craig, "Photonics for the space environment," Proc. $48^{\text {th }}$ IEEE Electronic Components and Technology Conference, pp. 391-394, 1998.

[13] R. Nagarajan, B. Li, R. Dato, P. Wen, P. Braid, K. Dzurko, and R.C. Craig., "Wide temperature (40 to $125^{\circ} \mathrm{C}$ ) uncooled operation of a single mode fiber packaged high speed data link at $1.2 \mathrm{~Gb} / \mathrm{s}$," Electron. Lett., vol. 32, no. 16, pp. 1493-1494, 1996.

[14] Y.M. Wong, et al., “Technology development of a high density 32 channel $16-\mathrm{Gb} / \mathrm{s}$ optical data link for optical interconnection applications for the Optoelectronic Technology Consortium (OETC), $J$. Lightwave Tech., vol. 13, no. 6, pp. 995-1016, 1995.

[15] H.E. Hager, E.Y. Chan, M.W. Beranek, and C.S. Hong, "VCSEL optical subassembly for avionics fiber-optic modules," Proc. of SPIE, vol. 2683, pp. 92-101, 1996.

[16] M.W. Beranek, E.Y. Chan, H.E. Hager and Q.N. Le, "Status of optoelectronic packaging for avionics/aerospace applications," Proc. IEEE Lasers and Electro-Optics Society $11^{\text {th }}$ Annual Meeting, pp. 329-330, 1998.

[17] J.S. Wilgus, M.W. Beranek, E.Y. Chan, H.E. Hager and Q.N. Le, "Potential opportunities for utilizing commercial optoelectronics in avionics fiber-optic networks," Proc. $18^{\text {th }}$ Digital Avionics
Systems Conference, vol. I, pp. 3.A.2-1 to 3.A.2-8, 1999.

[18] M.W. Beranek, E.Y. Chan, C.C. Chen, K.W. Davido, H.E. Hager, C.S. Hong, D.G. Koshinz, M. Rassaian, H.P. Soares, Jr., R.L. St. Pierre, P.J. Anthony, M.A. Cappuzzo, J.V. Gates, L.T. Gomez, G.E. Henein, J. Shmulovich, M.A. Occhionero and K.P. Fennessy, "Passive alignment optical subassemblies for military/ aerospace fiber-optic transmitter/receiver modules," IEEE Transactions on Advanced Packaging, vol. 23, no. 3, pp. 461469, 2000.

[19] C.R. Witham, M.W. Beranek, B.R. Carlisle, E.Y. Chan and D.G. Koshinz, "Automated fiberoptic pigtail assembly and attachment alignment shift using a low cost robotic platform," Proc. $50^{\text {th }}$ IEEE Electronic Components and Technology Conference, pp. 21-25, 2000.

[20] J.M. Haake and M.W. Beranek, "In-package micro-aligner for fiber-optic packaging," Proc. $48^{\text {th }}$ Electronic Component and Technology Conference, pp. 1446-1449, 1998.

[21] E.Y. Chan, Q.N. Le and M.W.Beranek, "High performance, low-cost chip-on-board (COB) FDDI transmitter and receiver for avionics applications," Proc. $48^{\text {th }}$ IEEE Electronic Components and Technology Conference, pp. 410-417, 1998.

[22] H.G. Kellzi, "Low cost MCM-L fiber optic transmitter package," Proc. $48^{\text {th }}$ IEEE Electronic Components and Technology Conference, pp. 404409, 1998.[23\} E.Y. Chan, Q.N. Le, M.W. Beranek, Y. Huang, D.G. Koshinz and H.E. Hager, "A 12 channel multimode fiber-optic $1.0625 \mathrm{~Gb} / \mathrm{s}$ FibreChannel receiver based on COTS devices and MCM-L/COB/BGA packaging," IEEE Photonics Technology Letters, vol. 12, no. 11, pp. 1549-1551, 2000.

[24] M.D. Orr, J.T. Hartley, M.W. Beranek, E.Y. Chan, H.E. Hager, and C.S. Hong, "Universal detachable optical connector for military and commercial aerospace fiber-optic modules," Proc. of SPIE, vol. 2691, pp. 142-148, 1996.

[25] R. Stevens, "A building block concept for optical backplane interconnect systems," Proc. of SPIE, vol. 2295, pp. 58-69, 1994. 
[26] P. Risner and L. Zweidinger, "Qualification and screening results of COTS transceivers for avionics applications," Proc. IEEE LEOS Avionics Fiber Optics and Photonics Conference, pp. 52-53, 2006.

[27] J.M. Trewhella, M.M. Oprysko, H. Backhauss, M. Ritter and M. Cina, "Unibody plastic injectionmolded optical sub-assembly for large core fiber," Proc. $46^{\text {th }}$ IEEE Electronic Components and Technology Conference, pp. 1116-1121, 1996.[28] E.Y. Chan, M.W. Beranek, K.W. Davido, H.E. Hager, C.S. Hong and R.L. St. Pierre, "Challenges for developing low-cost avionics/aerospace-grade optoelectronic modules," Proc. $46^{\text {th }}$ IEEE Electronic Components and Technology Conference, pp. 1122-1129, 1996.

[29] E.Y. Chan, M.W. Beranek, and D.N. Harres, "Gigabit fiber optic transceiver technology evolution for avionics," Proc. IEEE Avionics Fiber-Optics and Photonics Conference, pp. 50-51, 2006.

[30] M.W. Beranek, "Fiber optic interconnect and optoelectronic packaging challenges for future generation avionics," Proc. of SPIE, vol. 6478, pp. 9-1-9-18, 2007.

[31] M.W. Beranek, and A.R. Avak, "Improving avionics fiber optic network reliability and maintainability," IEEE Aerospace and Electronic Society Systems (AESS) Magazine, vol. 22, no. 5, pp. 20-24, 2007.

[32] M.W. Beranek, R.B. Jenkins and R.J. Voigt, "Military avionics fiber optics and photonics packaging technology forecast," Proc. IEEE LEOS Avionics Fiber-Optics and Photonics Conference, 2007.

[33] J. Ma, Y. Huang and S.-T. Ho, "Monolithically integrated compact high-speed wideband wavelength tunable filter chip," Proc. IEEE LEOS
Avionics Fiber-Optics and Photonics Conference, pp. 66-67, 2006.

[34] S. Yin, J. Lee, Q. Chen and Q. Zhang, "Recent advances of all-fiber tunable filter and its applications to reconfigurable WDM add/drop module and tunable receiver," Proc. IEEE LEOS Avionics Fiber-Optics and Photonics Conference, pp. 62-63, 2006.

[35] L. A. Coldren, G. A. Fish, Y. Akulova, J. S. Barton, L. Johansson, and C. W. Coldren, "Tunable Semiconductor Lasers: A Tutorial," J. Lightwave Technol. vol. 22, pp. 193-202, 2004.

[36] M. Masanovic, J.A. Summers, A. TaukePedretti, V. Lai, J.S. Barton, L.A. Coldren, D.J. Blumenthal, T. Gibbons, L. Elgin and M. Zhang, "Integrated high performance tunable wavelength converter technologies for future terrestrial and avionic optical networks," Proc. IEEE LEOS Avionics Fiber-Optics and Photonics Conference, 2007.

[37] B. Jenkins and R. Voigt, "A mixed signal DWDM local area network using bi-directional add drop multiplexers," Proc. IEEE LEOS Avionics Fiber-Optics and Photonics Conference, pp. 1112, 2005.

[38] C.N. Jessop, R.B. Jenkins and R.J. Voigt, "Routing in an optical local area network using wavelength conversion," Proc. IEEE LEOS Avionics Fiber-Optics and Photonics Conference, pp. 24-25, 2006.

[39] A. Glista, Jr. and M.W. Beranek, "Wavelength division multiplexed (WDM) optical technology solutions for next generation aerospace networks," Proc. $22^{\text {nd }}$ Digital Avionics Systems Conference, pp. 11.D.1-1- 11.D.1.13, 2003.

26th Digital Avionics Systems Conference October 21, 2007 